\title{
SHORT TERM AND LONG-TERM OUTCOMES OF LEFT MAIN PCI AT AFIC-NIHD
}

\author{
Samra Rehmat, Tahir Iqbal, Shaheer Farhan, Ariz Samin, Sajid Khan, Hafsa Kalil, Jasia Bukhari, Shoaib Safi \\ Armed Forces Institute of Cardiology/National Institute of Heart Disease (AFIC/NIHD)/National University of Medical Sciences (NUMS) \\ Rawalpindi Pakistan
}

\begin{abstract}
Objective: To study the short-term and long-term outcomes of left main angioplasty at AFIC-NIHD. Study Design: Descriptive cross-sectional study.

Place and Duration of Study: Armed Forces Institute of Cardiology/National Institute of Heart Disease (AFIC/NIHD) in 2018.

Methodology: All cases of left main angioplasty done in 2018 were included in the study. The patients were followed up in clinic or on telephone and mortality (in-hospital, 30 days) outcomes and survival duration were recorded. Kaplan Meier curves were generated to show the survival difference between those who underwent primary or elective LMPCI and survival difference between patients based on extent of coronary artery disease.

Results: A total of 73 patients underwent elective or primary left main angioplasty. The extent of coronary artery disease was: single vessel coronary artery disease (26\%), double vessel coronary artery disease $(37 \%)$, and three vessel coronary artery disease $(37 \%)$. Thirteen patients $(17.8 \%)$ had primary left main angioplasty, and 60 patients $(82.2 \%)$ had elective left main angioplasty. Intravascular ultrasound was performed in only 3 patients. The mean duration of follow up was 395 days. A total of $6(8.2 \%)$ patients died. Three patients died in-hospital, another 2 within the first 30 days, and the remaining beyond 30 days. Two of the dead patients had double vessel coronary artery disease, and 4 had three vessel coronary artery disease. The survival difference between the primary vs elective groups was insignificant (Log Rank (Mantel-Cox) $(p=0.27)$. The survival difference between the 3 groups with different extent of coronary artery disease was insignificant $(p=0.15)$.

Conclusion: Left main PCI is a safe procedure with acceptable outcomes. Patients with more severe coronary artery disease tend to fare worse.
\end{abstract}

Keywords: Angioplasty, Left main, Primary angioplasty.

This is an Open Access article distributed under the terms of the Creative Commons Attribution License (http://creativecommons.org/licenses/by/4.0), which permits unrestricted use, distribution, and reproduction in any medium, provided the original work is properly cited.

\section{INTRODUCTION}

The Left main coronary artery-with its branches, the left anterior descending and the circumflex is the main blood supply to the heart. ${ }^{1}$ According to the Syntax score, even in a right dominant system $16 \%$ of the myocardium is supplied by the left coronary artery. In a left dominant system where the Posterior descending artery arises from the left circumflex coronary artery, the left main coronary artery virtually supplies the entire heart ${ }^{2}$. Left main coronary artery disease significantly affects survival in sta-ble coronary artery disease and in acute coronary syndromes ${ }^{3,4}$. Treatment of left main coronary artery diseasewith coronary artery bypass graft surgery vs percutaneous coronary angioplasty has long been a

Correspondence: Dr Samra Rehmat, Cardiology Department, AFIC/NIHD Rawalpindi Pakistan subject for debate. ${ }^{5}$

\section{METHODOLOGY}

It was a retrospective, descriptive crosssectional study conducted at AFIC-NIHD. We accessed the hospital database to collect all cases of left main angioplasty (LMPCI) done in 2018. Baseline demographics, risk factors, and procedural details were collected for all patients who underwent primary or elective LMPCI during this period. We also sought to see the survival of the patients who underwent LMPCI. The clinical characteristics recorded for all subjects included age, gender, and clinical risk factor profile including diabetes mellitus, hypertension and smoking. Serum creatinine levels pre and post procedure were also noted. The patients were also stratified based on the angiographic involvement of other coronary vessels and whether the LMPCI 
was elective or primary. The patients were followed up in clinic or on telephone and mortality was recorded. The outcome measure was mortality (in-hospital, 30 days). Their vital status and survival duration was also recorded.

Statistical analysis was performed using SPSS software (SPSS Inc, Chicago, IL, USA, version SPSS v23). Categorical data was expressed as percentages, and continuous variables as mean \pm SD or median (interquartile range), as appropriate. For comparison of normally distributed variables, Student's t-test was applied. Categorical variables were tabulated and frequencies recorded. All values were reported as mean \pm SD and a $p$-value of less than 0.05 was considered statistically significant. Kaplan Meier curves were generated to show the mortality difference between the 2 groups of patients who underwent primary or elective LMPCI and also to demonstrate the difference in survival between patients based on extent of coronary artery disease.

\section{RESULTS}

A total of 73 patients underwent elective or primary LMPCI in the duration of the study. There were $87.7 \%$ (64) males and $12.3 \%$ (females) in the study. Mean age was $62.9 \pm 8.36$ years (min 35; max 82). The percentage of Diabetics, hypertensive and smoking patients in the study population was $50.7 \%, 47.9 \%$ and $9.6 \%$ respectively. The extent of coronary artery disease was almost equally split between single vessel coronary artery disease (SVCAD 26\%), double vessel coronary artery disease (DVCAD 37\%), and three vessel coronary artery disease (TVCAD 37\%). Thirteen patients $(17.8 \%)$ had primary LMPCI, and 60 patients $(82.2 \%)$ had elective LMPCI. Mean pre and post procedure serum creatinine levels were $1.12 \pm 0.25 \mathrm{mg} / \mathrm{dL}$, and $1.28 \pm 0.7 \mathrm{mg} /$ $\mathrm{dL}(p=0.04)$. Intravascular ultrasound (IVUS) was performed in only 3 patients.

The mean duration of follow up was 395 days. A total of $6(8.2 \%)$ patients died. Of these 2 patients were in the primary group, and 4 were in the elective group. Three patients died inhospital, another 2 within the first 30 days, and the remaining beyond 30 days. Two of the dead patients had DVCAD, and 4 had TVCAD. None of the patients with SVCAD expired after PCI. The Kaplan Meier survival curves for the primary vs elective groups are shown in fig- 1 . The survi-

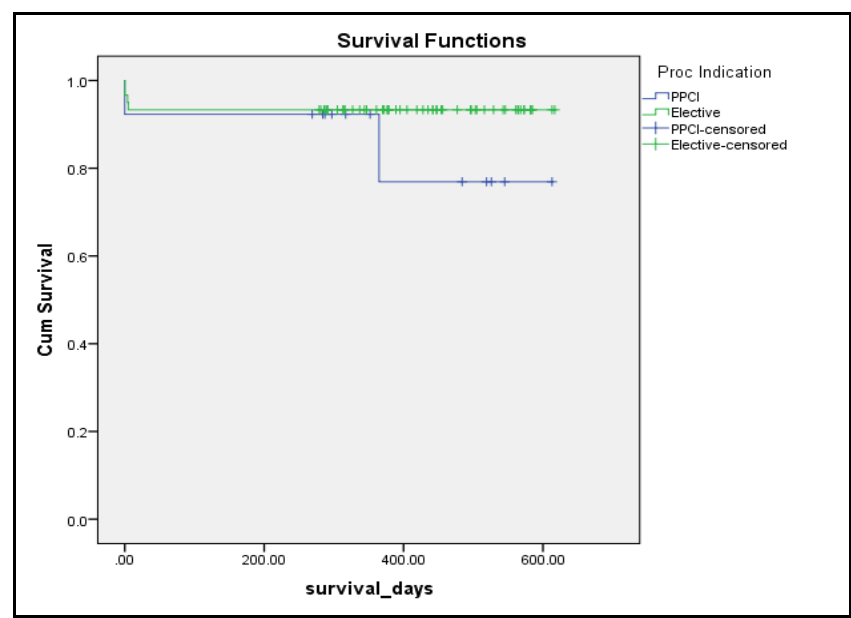

Figure-1: Kaplan meier survival curves for the primary vs elective groups.

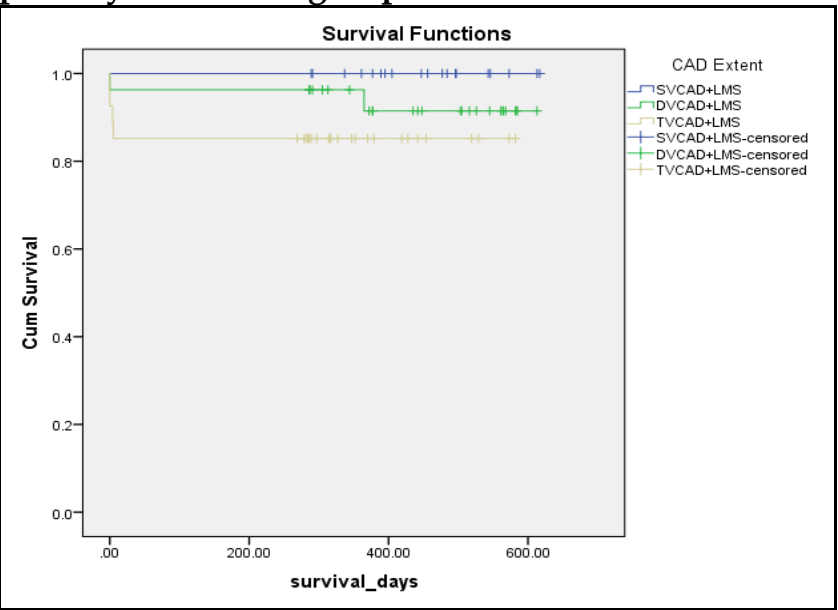

Figure-2: The kaplan meier survival curves based of the difference in the extent of coronary artery disease.

val difference between the 2 groups was insignificant (Log Rank (Mantel-Cox) $p=0.27$ ). Fig-2 shows the Kaplan Meier survival curves based on the difference in the extent of coronary artery disease. The survival difference between the 3 groups was insignificant (LogRank (Mantel-Cox) $p=0.15$ ). Three patients had PCI to Ostial LM (all alive); 47 had PCI LMS to LAD (3 dead); 10 had LMS to LCx (2 Dead); and 13 had distal LMS bifurcation PCI of which 1 died. 


\section{DISCUSSION}

The debate of CABG vs PCI for LMCAD and multivessel coronary artery disease is an old one. One of the first randomized controlled trials, the Bypass Angioplasty Revascularization Investigation (BARI) trial showed that 5-year cardiac mortality in patients with multivessel disease was significantly greater after initial treatment with PTCA than with CABG ${ }^{6}$. With the improvements in technology and techniques for angioplasty however, the repertoire of coronary lesions amenable to angioplasty has expanded. In a further study the BARI investigators identified that factors most strongly associated with high overall mortality rates were insulin-treated diabetes, congestive heart failure, kidney failure, and older age $^{7}$. These investigators further showed that in the BARI trial population, patients who were alive at 5 years, initial treatment assignment to angioplasty or CABG was not associated with any difference in long-term ventricular function ${ }^{8}$. Further evidence in this area came from the Syntax (Synergy Between PCI With Taxus and Cardiac Surgery) trial. Syntax was a trial that took into account the anatomical complexity of the coronary artery disease based on a scoring system that stratified patients into high, intermediate and low risk for PCI. This trial compared PCI and CABG for treating patients with previously untreated three-vessel or left main coronary artery disease (or both). Rates of major adverse cardiac or cerebrovascular events at 12 months were significantly higher in the PCI group $(17.8 \%$, vs. $12.4 \%$ for CABG; $p=0.002$ ), in large part because of an increased rate of repeat revascularization (13.5\% vs. $5.9 \%, p<0.001)$. At 12 months, the rates of death and myocardial infarction were similar between the two groups; stroke was significantly more likely to occur with CABG $(2.2 \%$, vs. $0.6 \%$ with PCI; $p=0.003)$. The syntax trialists concluded that CABG remains the standard of care for patients with three-vessel or left main coronary artery disease, since the use of CABG, as compared with $\mathrm{PCI}$, resulted in lower rates of the combined end point of major adverse cardiac or cerebrovascular events at 1 year' .
Based on the Syntax anatomical scoring system there were patients with isolated left main disease, or those with left main disease and coronary artery disease that was not so extensive who fell into the intermediate score group. The LM patients treated with PCI-and CABG-treated Syntax population were reviewed at 5 years. Stroke was significantly increased in the CABG group (PCI 1.5\% versus CABG $4.3 \%$; hazard ratio, 0.33 [95\% confidence interval, 0.12-0.92]; $p=0.03$ ) and repeat revascularization in the PCI arm $(26.7 \%$ versus $15.5 \%$; hazard ratio, 1.82 [95\% confidence interval, 1.28-2.57]; $p<0.01$ ). Major adverse cardiac and cerebrovascular events were similar between arms in patients with low/intermediate Syntax scores but significantly increased in PCI patients with high scores $(\geq 33)^{10,11}$. In the Syntax cohort, at 10 years, no significant difference existed in allcause death between PCI using first-generation paclitaxel-eluting stents and CABG. However, CABG provided a significant survival benefit in patients with three-vessel disease, but not in patients with left main coronary artery disease ${ }^{12}$. The 5 year outcomes of PCI compared with CABG for the treatment of unprotected left main coronary artery stenosis were studied in the PRECOMBAT (Premier of Randomized Comparison of Bypass Surgery Versus Angioplasty Using Sirolimus-Eluting Stent in Patients With Left Main Coronary Artery Disease) trial. During 5 years of follow-up, the study did not show significant difference regarding the rate of MACCE between patients who underwent PCI with a sirolimus-eluting stent and those who underwent CABG. The authors however, cautioned towards the limited power of their study ${ }^{13}$. The PRECOMBAT-2 stuy sought to evaluate the safety and efficacy of second-generation drug-eluting stents (DES) for patients with unprotected left main coronary artery stenosis. They concluded that the Secondgeneration EES had a similar 18-month risk of MACCE for ULMCA stenosis as first-generation SES or CABG ${ }^{14}$. Pooled data from the SYNTAX, PRECOMBAT, and BEST (Randomized Comparison of Coronary Artery Bypass Surgery and Everolimus-Eluting Stent Implantation in the 
Treatment of Patients With Multivessel Coronary Artery Disease) trials showed that for the treatment of left main or multivessel coronary artery disease, PCI resulting in complete revascularization was associated with a similar long-term survival rate to CABG resulting in complete revascularization. Therefore, the ability to achieve complete revascularization also should enter into the decision algorithm for choice of revascularization strategy ${ }^{15}$. The French left main registry also showed that LM PCI is a safe option. Unprotected LM stenting with paclitaxel-eluting stents, with a strategy of provisional side-branch T-stenting for distal lesions, provides excellent acute angiographic results and good mid-term clinical outcomes, with a $15.8 \%$ rate of major adverse cardiac events at 2-year follow-up ${ }^{16}$.

Recently the results of the EXCEL trial showed that in patients with left main coronary artery disease of low or intermediate anatomical complexity, there was no significant difference between PCI and CABG with respect to the rate of the composite outcome of death, stroke, or myocardial infarction at 5 years ${ }^{17}$. The 5 -year outcomes from the NOVEL trial showed that in revascularisation of left main coronary artery disease, PCI was associated with an inferior clinical outcome at 5 years compared with CABG. Mortality was similar after the two procedures but patients treated with PCI had higher rates of non-procedural myocardial infarction and repeat revascularisation ${ }^{18}$.

The current data shows LM PCI to be a safe procedure in a select group of patients. $\mathrm{T}$ he extent of coronary artery disease with the LMS disease dictates the outcomes. In our study the patients with more severe coronary artery disease along with the LM disease had worse outcomes.

\section{ACKNOWLEDGMENT}

We the authors dedicate this article to the late Dr Tahir Iqbal, who contributed his wisdom to the work; a mentor, doctor, great human being. May his soul rest in peace.

\section{CONCLUSION}

Left main PCI is a safe procedure with acceptable outcomes. Patients with more severe coronary artery disease tend to fare worse.

\section{CONFLICT OF INTEREST}

This study has no conflict of interest to be declared by any author.

\section{REFERENCES}

1. Kastellanos S, Aznaouridis K, Vlachopoulos C, Tsiamis E, Oikonomou E, Tousoulis D. Overview of coronary artery variants, aberrations and anomalies. World J Cardiol 2018; 10(10): 127-40.

2. Sianos G, Morel MA, Kappetein AP, Morice MC, Colombo A, Dawkins K. The Syntax Score: an angiographic tool grading the complexity of coronary artery disease. Euro Intervention: Journal of Euro PCR in collaboration with the Working Group on Interventional Cardiology of the European Society. Cardiol 2005; 1(2): 219-27.

3. Palmerini T, Serruys P, Kappetein AP, et al. Clinical outcomes with percutaneous coronary revascularization vs coronary artery bypass grafting surgery in patients with unprotected left main coronary artery disease: a meta-analysis of 6 randomized trials and 4,686 patients. Am Heart J 2017; 190: 54-63.

4. Chieffo A, Tanaka A, Giustino G. The DELTA 2 registry: a multicenter registry evaluating percutaneous coronary intervention with new-generation drug-eluting stents in patients with obstructive left main coronary artery disease. Cardiovasc Interv 2017; 10: 2401-10.

5. Vaquerizo B, Lefèvre $T$, Darremont O. Unprotected left main stenting in the real world. Circulation 2009; 119(17): 2349-56.

6. Chaitman BR, Rosen AD, Williams DO, Bourassa MG, Aguirre FV, Pitt B, et al. Myocardial infarction and cardiac mortality in the Bypass Angioplasty Revascularization Investigation (BARI) randomized trial. Circulation 1997; 96(7): 2162-70.

7. Brooks MM, Jones RH, Bach RG, Chaitman BR, Kern MJ, Orszulak TA, et al. Predictors of mortality and mortality from cardiac causes in the bypass angioplasty revascularization investigation (BARI) randomized trial and registry. For the BARI Investigators. Circulation 2000; 101(23): 2682-89.

8. Gibbons RJ, Miller DD, Liu P, Guo P, Brooks MM and Schwaiger M. Similarity of ventricular function in patients alive 5 years after randomization to surgery or angioplasty in the BARI trial. Circulation 2001; 103(8): 1076-82.

9. Serruys PW, Morice MC, Kappetein AP, Colombo A, Holmes DR, Mack MJ, et al. Percutaneous coronary intervention versus coronary-artery bypass grafting for severe coronary artery disease. N Engl J Med 2009; 360(10): 961-72.

10. Morice MC, Serruys PW, Kappetein AP, Feldman TE, Stahle E, Colombo A, et al. Five-Year Outcomes in Patients With Left Main Disease Treated With Either Percutaneous Coronary Intervention or Coronary Artery Bypass Grafting in the Synergy Between Percutaneous Coronary Intervention With Taxus and Cardiac Surgery Trial. Circulation 2014; 129(23): 2388-94.

11. Park DW, Ahn JM, Park SJ and Taggart DP. Percutaneous coronary intervention in left main disease: Syntax, Precombat, Excel and NOBLE-combined cardiology and cardiac surgery 
perspective. Ann Cardiothorac Surg 2018; 7(4): 521-26.

12. Thuijs D, Kappetein AP, Serruys PW, Mohr FW, Morice MC, Mack MJ, et al. Percutaneous coronary intervention versus coronary artery bypass grafting in patients with three-vessel or left main coronary artery disease: 10-year follow-up of the multicentre randomised controlled SYNTAX trial. Lancet 2019; 394(10206): 1325-34.

13. Ahn JM, Roh JH, Kim YH, Park DW, Yun SC, Lee PH, et al. Randomized trial of stents versus bypass surgery for left main coronary artery disease: 5-year outcomes of the PRECOMBAT study. J Am Coll Cardiol 2015; 65(20): 2198-06.

14. Kim YH, Park DW, Ahn JM, Yun SC, Song HG. Everolimuseluting stent implantation for unprotected left main coronary artery stenosis. The PRECOMBAT-2 (Premier of Randomized Comparison of Bypass Surgery versus Angioplasty Using Sirolimus-Eluting Stent in Patients with Left Main Coronary Artery Disease) study. JACC Cardiovasc Interv 2012; 5(7): 708-17.

15. Ahn JM, Park DW, Lee CW, Chang M, Cavalcante R, Sotomi Y, et al. Comparison of Stenting Versus Bypass Surgery According to the Completeness of Revascularization in Severe Coronary Artery Disease: Patient-Level Pooled Analysis of the Syntax, Precombat, and BEST Trials. Cardiovasc Interv 2017; 10(14): 1415-24.

16. Vaquerizo B, Lefevre T, Darremont O, Silvestri M, Louvard $Y$, Leymarie JL, et al. Unprotected left main stenting in the real world: two-year outcomes of the French left main taxus registry. Circulation 2009; 119(17): 2349-56.

17. Stone GW, Kappetein AP, Sabik JF, Pocock SJ, Morice MC, Puskas J, et al. Five-Year Outcomes after PCI or CABG for Left Main Coronary Disease. New Eng J Med 2019; 381(1): 1820-30.

18. Holm NR, Mäkikallio T, Lindsay MM, Spence MS, Erglis A, Menown IBA, et al. Percutaneous coronary angioplasty versus coronary artery bypass grafting in the treatment of unprotected left main stenosis: updated 5-year outcomes from the randomised, non-inferiority NOBLE trial. Lancet 2020; 395(19): 191-99. 